\title{
Sinusoidal Immunity: Macrophages at the Lymphohematopoietic Interface
}

\author{
Siamon Gordon ${ }^{1}$, Annette Plüddemann², and Subhankar Mukhopadhyay ${ }^{1,3}$ \\ ${ }^{1}$ Sir William Dunn School of Pathology, University of Oxford, Oxford OX1 3RE, United Kingdom \\ ${ }^{2}$ Department of Primary Care Health Sciences, University of Oxford, Oxford OX2 6GG, United Kingdom \\ ${ }^{3}$ Wellcome Trust Sanger Institute, Hinxton, Cambridge CB10 1SA, United Kingdom \\ Correspondence: siamon.gordon@path.ox.ac.uk
}

\begin{abstract}
Macrophages are widely distributed throughout the body, performing vital homeostatic and defense functions after local and systemic perturbation within tissues. In concert with closely related dendritic cells and other myeloid and lymphoid cells, which mediate the innate and adaptive immune response, macrophages determine the outcome of the inflammatory and repair processes that accompany sterile and infectious injury and microbial invasion. This article will describe and compare the role of specialized macrophage populations at two critical interfaces between the resident host lymphohematopoietic system and circulating blood and lymph, the carriers of cells, humoral components, microorganisms, and their products. Sinusoidal macrophages in the marginal zone of the spleen and subcapsular sinus and medulla of secondary lymph nodes contribute to the innate and adaptive responses of the host in health and disease. Although historically recognized as major constituents of the reticuloendothelial system, it has only recently become apparent that these specialized macrophages in close proximity to B and T lymphocytes play an indispensable role in recognition and responses to exogenous and endogenous ligands, thus shaping the nature and quality of immunity and inflammation. We review current understanding of these macrophages and identify gaps in our knowledge for further investigation.
\end{abstract}

$T^{\mathrm{h}}$ he origin, distribution, and functions of cells of the mononuclear phagocyte system have been redefined by a resurgence of studies in the past decade, mostly in the mouse and to a limited extent in human (Davies et al. 2013). Progress has been made regarding the production and migration of monocytes and macrophages during embryonic and adult life, giving rise to resident cell populations in hematopoietic and nonlymphohematopoietic organs, such as liver, lung, gut, skin, and the central nervous system (CNS) (Schulz et al. 2012; Hashimoto et al. 2013; Yona et al. 2013). Blood-derived monocytes contribute new migrants, that give rise to tissue monocytes, macrophages, and dendritic cells (DCs), which all contribute to the inflammatory and immune response to infection and tissue injury (Cheong et al. 2010; Reizis 2012). A great deal has been learned regarding the versatility and plasticity of macrophages in response to microbial and self-constituents, their extensive endocytic and secretory capacity,

Editor: Ruslan M. Medzhitov

Additional Perspectives on Innate Immunity and Inflammation available at www.cshperspectives.org

Copyright (C) 2015 Cold Spring Harbor Laboratory Press; all rights reserved; doi: 10.1101/cshperspect.a016378

Cite this article as Cold Spring Harb Perspect Biol 2015;7:a016378 


\section{S. Gordon et al.}

and the ability to discriminate between host and foreign ligands (Gordon 2012). Much of our current understanding derives from in vitro cell culture, supplemented by in vivo genetic and infectious experimental models, mainly in the mouse.

Early studies of particle clearance, including bacterial capsular polysaccharides (Humphrey and Grennan 1981; Zamze et al. 2002) and other tracers from blood, revealed the presence of sinus-lining phagocytes in liver (Kupffer cells) (Jenne and Kubes 2013), in spleen, and in bone marrow (Moghimi et al. 2012). The discovery of the circulation of lymphocytes (Gowans 1991) and numerous experimental immunization protocols initiated extensive research into lymphoid structure, lymphocyte migration, subsets, and functions. The development of monoclonal antibodies and of fluorescent imaging techniques combined with traditional histological techniques helped to define the distribution of resident macrophages in mouse tissues and drew attention to specialized anatomical regions in spleen and lymph nodes (LNs), in which blood and lymph directly reach resident antigen capturing, processing, and presenting cells (APCs) (Figs. 1 and 2). Antigen marker studies in the mouse revealed strikingly different phenotypes of macrophage populations in the splenic MZ and LN SCS, compared with other resident tissue macrophages (Figs. 3 and 4). Although in situ studies provided useful glimpses of function, the intrinsic difficulty of isolating these resident macrophages from tissue has limited their characterization. Furthermore, the marginal zone, although well defined in rodents, is not identifiable as a distinct structure in human spleen, depriving it of apparent interest. Although the two specialized structures share properties and perform analogous functions in LNs of human and mouse, their relationship has not been established.

In this review, we compare the properties of metallophilic and marginal zone macrophages in mouse spleen, and the SCS and medullary macrophages in mouse LNs, with those of other tissue macrophages; their properties and close proximity to resident lymphoid and other myeloid cells distinguish them from mucosal, hepatic, and other sinus-lining cells. Their similarity and specialization provide insights into the regulation of innate and adaptive immunity,
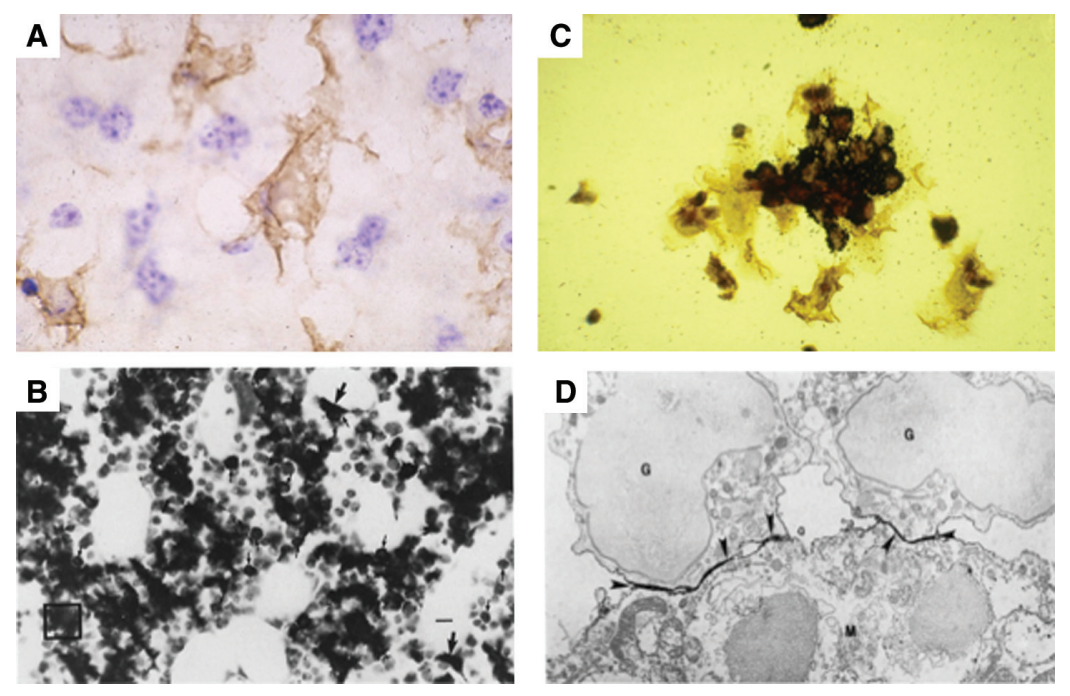

Figure 1. Sinusoidal resident tissue macrophages in the mouse. (A) F4/80 ${ }^{+}$Kupffer cells, distinct from F4/80sinusoidal endothelium and adjacent hepatocytes. Bone marrow stromal macrophages in situ $(B)$, and in vitro $(C)$. These $\mathrm{F} 4 / 80^{+}$macrophages associate with clusters of hematopoietic cells during their differentiation and express CD169 at sites of contact with myeloid cells (D). (From Hume et al. 1983 and Crocker et al. 1990; reprinted, with permission.) 


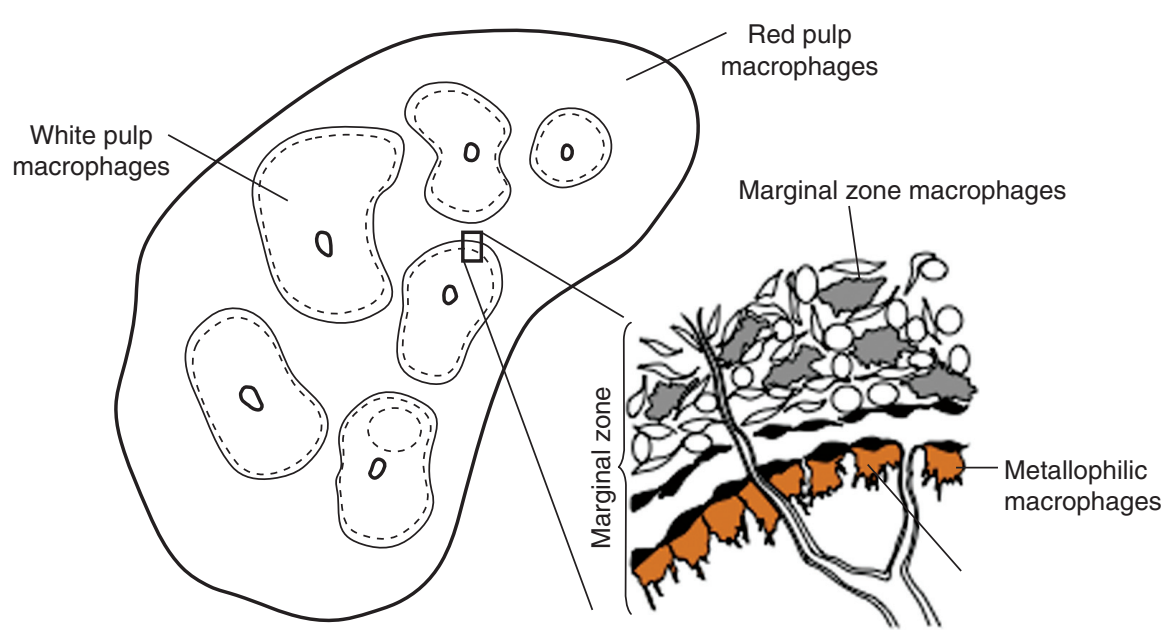

Lymph node

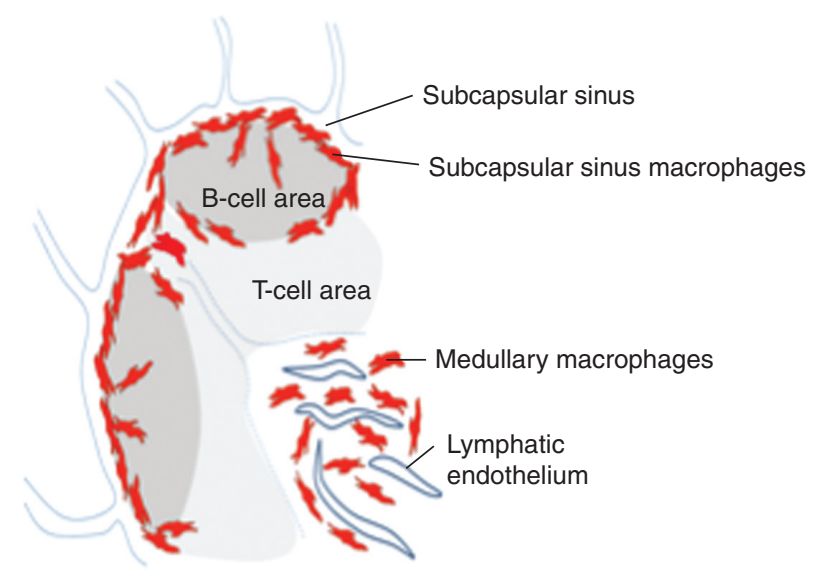

Figure 2. Schematic representation of mouse spleen and lymph node. Illustrating the lymphohematopoietic interface with specialized macrophages in close proximity to B- and T- lymphocyte populations. (From Gordon 2012 and Martinez-Pomares and Gordon 2012; adapted, with permission.)

but also indicate gaps in our knowledge to guide further study and manipulation. For further information, readers are referred to several excellent general reviews (Kraal 1992; den Haan and Kraal 2012; Gray and Cyster 2012), as well as selected references.

\section{ANATOMY}

\section{Spleen Marginal Zone}

The spleen is a complex organ consisting of hematopoietic and lymphoid compartments, the red and white pulp, respectively, separated in the normal adult mouse by the marginal zone (MZ), as illustrated in Figure 2. Arterial branches of the splenic artery are sheathed by $\mathrm{T}$ lymphocytes and B-cell follicles in the white pulp, and end in venous sinuses directly in the red pulp and MZ.

Antigen markers have aided the identification of distinct macrophage populations in the inner and outer MZs; characteristic sinuslining $\mathrm{CD} 169^{+} \mathrm{F} 4 / 80$-metallophilic (MMM) cells with an affinity for silver stains in the inner region (Fig. 4), and more phagocytic, 
S. Gordon et al.

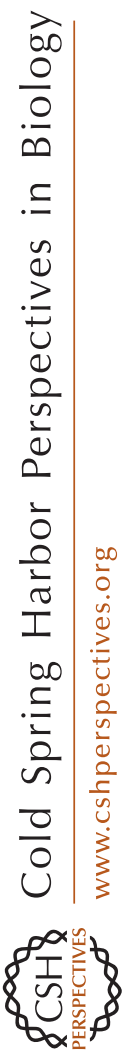

$\mathrm{MARCO}^{+} \mathrm{SIGNR}^{+}$macrophages in the outer zone (MZM). These macrophage populations can be distinguished from monocytes, mature macrophages, and DC in the red and white pulp, some of which also line sinusoids (Table 1). Other cells in the MZ include sinus-lining Madcam $^{+}$vascular endothelial cells, DCs, and B1 lymphocytes, as well as stromal fibroblasts (Kraal et al. 1995; Nolte et al. 2004; Mueller and Germain 2009; You et al. 2011). Finally, there is evidence for heterogeneity among metallophils in mouse spleen, defined by their abil- ity to bind $\mathrm{Fc}$-chimaeric probes containing the cysteine-rich domain of the mannose receptor, CD206 (Martinez-Pomares et al. 1996), as discussed further below.

The $\mathrm{MZ}$ varies during development (Morris et al. 1991; Morris et al. 1992), is influenced by inflammatory/immunologic stimuli (Benedict et al. 2006), and shows striking species differences (Steiniger et al. 1997; Milicevic et al. 2011). Ontogeny studies have shown that the MZ of mouse spleen develops postnatally over several weeks; depletion of macrophages 


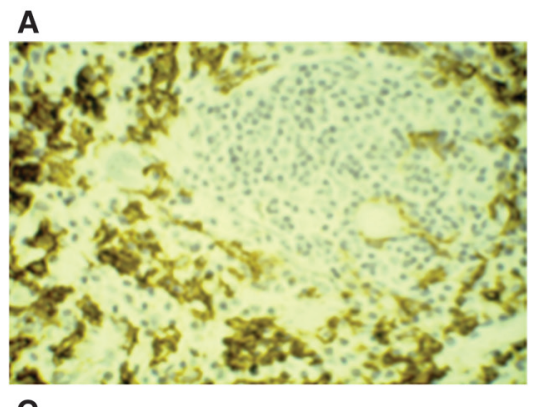

B

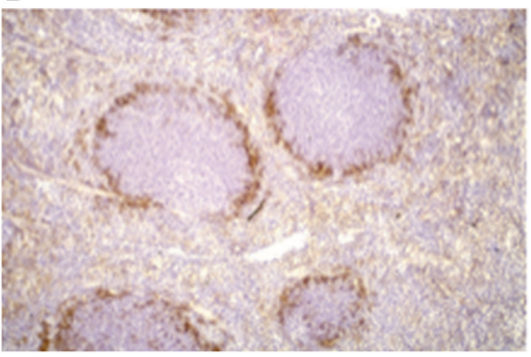

D

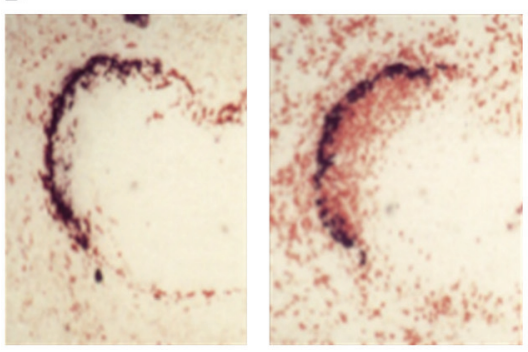

$\mathbf{F}$

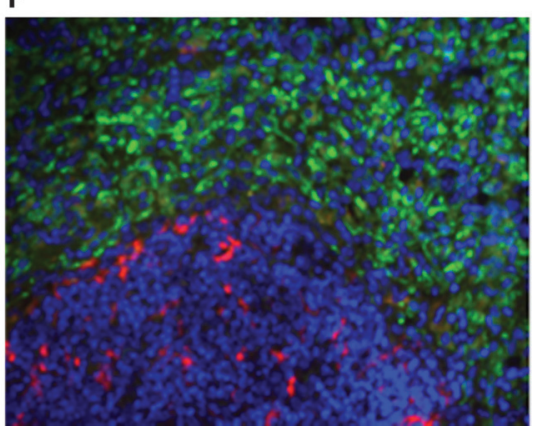

Figure 4. Immunocytochemistry of mouse spleen. (A) $\mathrm{F} 4 / 80^{+}$red pulp macrophages. Note the absence of F4/80 expression in marginal zone. $(B-F) C D 169^{+}$marginal metallophilic macrophages. $(C-F)$ Subpopulations of $\mathrm{CD}_{169}{ }^{+}$bind $\mathrm{CR}-\mathrm{Fc}$ and associate with $\mathrm{IgD}^{+}$B lymphocytes $(D$, panel on right). $E$ and $F$ illustrate induced migration of $\mathrm{CR}-\mathrm{Fc}^{+}$macrophages into white pulp after immune activation. (From Crocker and Gordon 1989 and Taylor et al. 2004; reprinted, with permission, from The Rockefeller University (C) 1989 and the authors.)

by clodronate-loaded liposomes (Wijffels et al. 1994) is followed by relatively slow recovery of $\mathrm{MZ} \mathrm{MARCO}^{+}$macrophages, compared with that of other phagocytes (Kraal et al. 2000). The macrophage growth factor CSF-1 (MCSF) is required for the appearance of CD169 ${ }^{+}$ metallophils in wild-type mice, as shown by their absence in CSF-1 deficient osteopetrotic mutant mice (Fig. 5) (Witmer-Pack et al. 1993). The absence of F4/80 expression by MMM is striking (Figs. 4 and 6).
The $\mathrm{CD} 169^{+}$MMM line B-cell follicles at the border of the marginal sinus; their presence depends on lymphotoxin $\alpha 1 \beta 2$ (LT $\alpha 1 \beta 2)$ produced by follicular B cells (Zindl et al. 2009), and LT may also be necessary for the appearance of $\mathrm{MARCO}^{+}$macrophages in the outer $\mathrm{MZ}$ (Fig. 6).

The MZ is a prominent multilayered structure in the rat (Steiniger et al. 2006). The human spleen lacks the characteristic organization found in rodents (Steiniger et al. 1997), but 
S. Gordon et al.

Table 1. Selected markers of murine sinusoidal macrophages

\begin{tabular}{|c|c|c|}
\hline \multirow[t]{7}{*}{ Spleen } & $\begin{array}{l}\text { Marginal zone } \\
\text { metallophilic } \\
\text { macrophages }\end{array}$ & 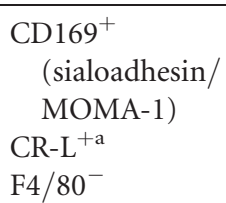 \\
\hline & Outer marginal & $\mathrm{MARCO}^{+}$ \\
\hline & zone & SIGN-R $1^{+}$ \\
\hline & macrophages & $\mathrm{F} 4 / 80^{-}$ \\
\hline & Red pulp & $\mathrm{F} 4 / 80^{+}$ \\
\hline & macrophages & $\mathrm{MR}^{+}$ \\
\hline & & CD169 dim \\
\hline \multirow[t]{8}{*}{ Lymph node } & Subcapsular sinus & $\mathrm{CD} 169^{+}$ \\
\hline & macrophages & $\mathrm{CR}_{-} \mathrm{L}^{+}$ \\
\hline & & $\mathrm{F} 4 / 80^{-}$ \\
\hline & Medullary & $\mathrm{CD} 169^{+/-}$ \\
\hline & macrophages & $\mathrm{F} 4 / 80^{+}$ \\
\hline & & SIGN-R1 ${ }^{+}$ \\
\hline & & $\mathrm{MARCO}^{+}$ \\
\hline & & $\mathrm{MR}^{+}$ \\
\hline \multirow[t]{2}{*}{ Bone marrow } & Stromal & $\mathrm{F} 4 / 80^{+}$ \\
\hline & macrophages & $\mathrm{CD} 169^{+}$ \\
\hline \multirow[t]{4}{*}{ Liver } & Kupffer cells & $\mathrm{F} 4 / 80^{+}$ \\
\hline & & $\mathrm{CD} 169^{-/+}$ \\
\hline & & $\mathrm{MR}^{+}$(also \\
\hline & & $\begin{array}{l}\text { endothelium) } \\
\text { SR-A }^{+} \text {(also } \\
\text { endothelium) }\end{array}$ \\
\hline
\end{tabular}

${ }^{\mathrm{a}}$ Ligand for cysteine-rich domain of MR.

$\mathrm{CD} 169^{+}$macrophages, which are present in interfollicular regions, may represent an homologous population, as discussed below.

\section{Lymph Node Subcapsular Sinus}

The structure of mouse LNs is illustrated in Figure 2. Several afferent lymphatics enter a single LN and pass into a narrow subcapsular sinus (SCS), which overlies the lymphocyterich cortex. Conduits (Roozendaal et al. 2008; Moussion and Sixt 2013) deliver lymph to the medullary region, which contains numerous irregularly shaped, interconnected sinuses, and medullary cords from which it is collected into an efferent lymphatic vessel. Larger LN in the human also contain trabecular sinuses, which radiate from SCS through parenchyma, providing an additional path for lymphatic flow.
Subcapsular sinus macrophages (SSMs) line the floor of the SCS, lying over lymphoid follicles. SSMs are quick to capture small amounts of lymph-borne substances (Figs. 7 and 8), but are poorly phagocytic compared with medullary sinus macrophages (MSMs), which are highly phagocytic, evident through their abundant phagolysosomes. SSMs display limited motility, unlike DCs, and have long stable tails extending across the lymphatic lining layer, as well as head and neck regions. MSMs adhere to the sinus walls and traversing reticular fibers in their lumen, which also contains lymphocytes. Cortical sinuses are packed with lymphocytes; as lymph flows toward the medullary sinus and cords, it contains macrophages, fewer lymphocytes, DCs, and variable numbers of plasma cells, depending on prior immune stimulation. The cords often contain a blood vessel. Neutrophils are present after inflammation.

Lymphoid follicles, germinal centers, and follicular dendritic cells (FDCs) are well described elsewhere (MacLennan 2005; Kastenmuller et al. 2012). The paracortex and interfollicular regions contain a range of immune cells: DCs, natural killer (NK), natural killer $\mathrm{T}$ (NKT), innate lymphoid cells (ILCs), and $\gamma / \delta$ lymphocytes, as well as scattered B and T (CD4 and innate-like CD8) cells, some of which are prepositioned to interact with SSM and antigens, as discussed below. Finally, the LN stroma contains heterogeneous mesenchymal cells (Castagnaro et al. 2013) and blood vessels, including High endothelial venules (HEV), for homing of recirculating lymphocytes.

LNs can vary substantially, depending on their location and drainage, for instance, in the mesentery or at peripheral sites, as well as after antigen stimulation. The origin and turnover of different LN macrophage populations has not been fully characterized. Resident SSMs develop postnatally, and is in part dependent on M-CSF (Witmer-Pack et al. 1993) and lymphotoxin. The expansion of macrophages after immunization involves recruitment and local proliferation; cells can emigrate or die by apoptosis. Experimental depletion by clodronate liposomes has revealed differential repopulation from bone marrow precursors and 

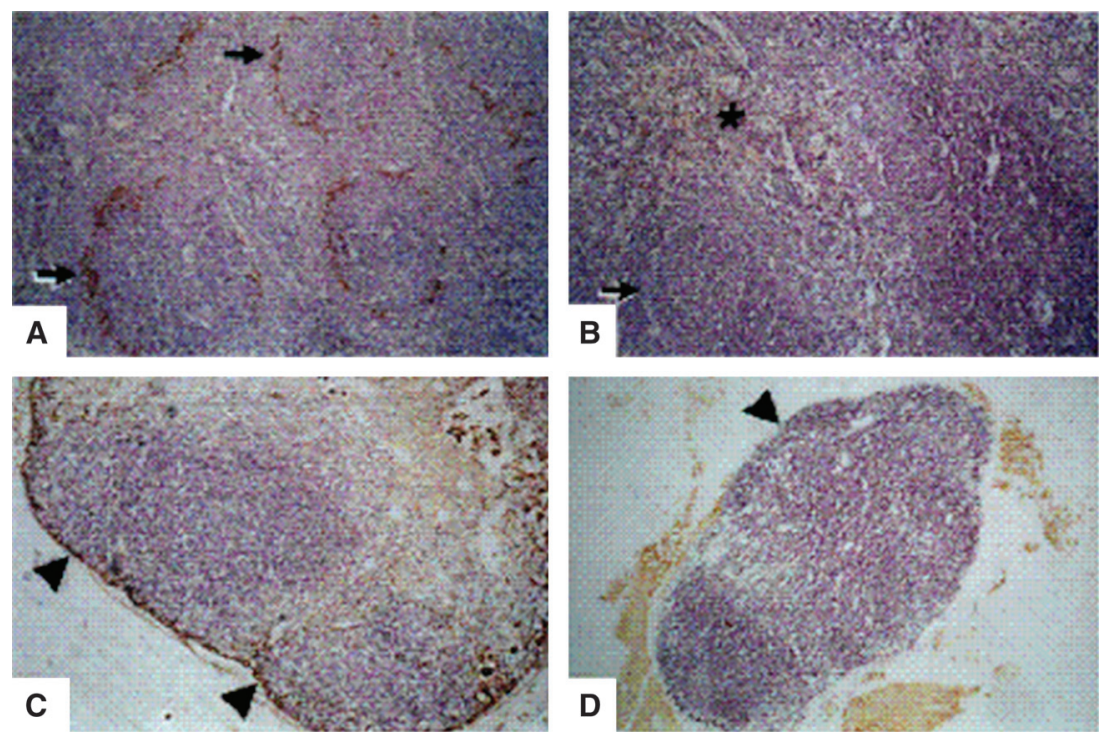

Figure 5. Spleen and lymph node in wild type and CSF-1-deficient op/op mice. CD169 expression by marginal metallophilic macrophages $(A, B)$, and subcapsular macrophages $(C, D)$ depends on CSF-1. (From Witmer-Pack et al. 1993; reprinted, with permission, from the authors.)

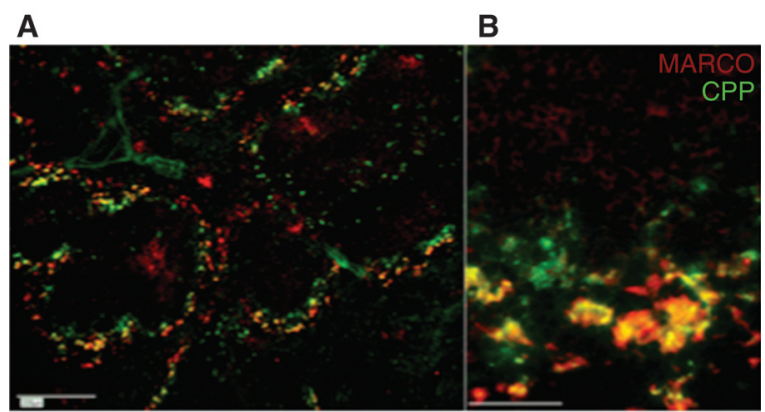

C

D
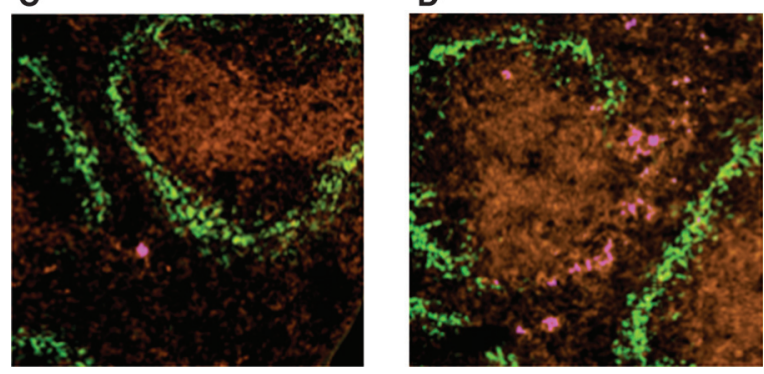

Figure 6. Functions of marginal zone macrophages. $(A, B)$ Splenic $\mathrm{MARCO}^{+}$marginal zone macrophages clear calciprotein particles from the circulation. (From Herrmann et al. 2012; reprinted, with permission.) (C,D) F4/ $80^{+}$APC (magenta) localize to marginal zone of spleen after induction of tolerance to antigen delivered into the anterior chamber of the eye; $\mathrm{CD}_{169^{+}}$marginal metallophilic macrophages in green. (From Lin et al. 2005; reprinted, with permission, from the authors.) 
S. Gordon et al.
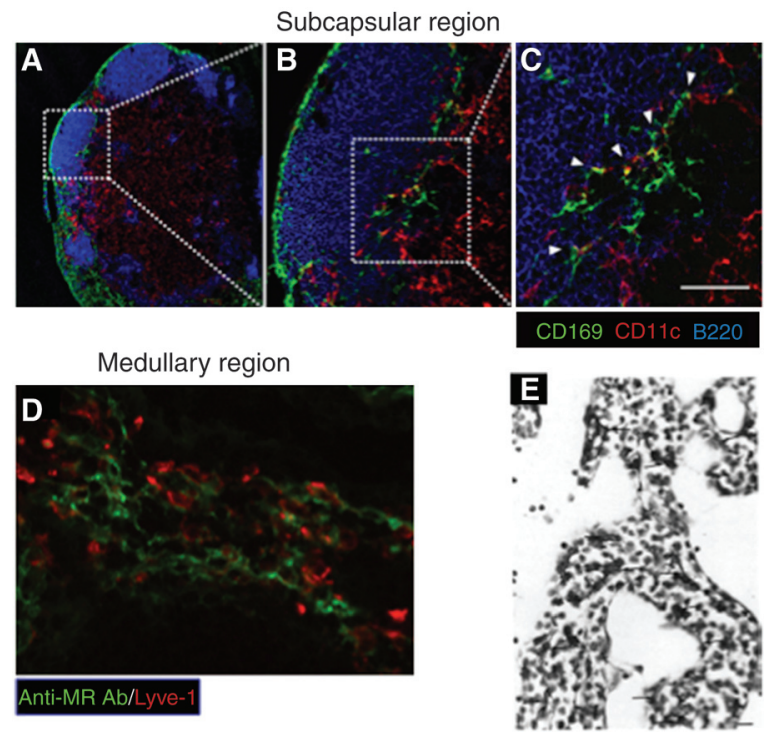

Figure 7. Sinusoidal macrophages in lymph node. $(A-C) \mathrm{CD}_{169}{ }^{+}$subcapsular sinus macrophages in proximity to $\mathrm{CD} 11 \mathrm{c}^{+} \mathrm{DC}$ and B220 $\mathrm{B}$ lymphocytes. Scale bar, $50 \mu \mathrm{m}$. (D) Adjacent cells in the medullary sinus express MR and Lyve-1. (E) F4 $/ 80^{+}$macrophages in the medulla. (A-D, From Asano et al. 2011; reprinted, with permission, from the authors; $E$, from Hume et al. 1983; reprinted, with permission, from the authors.)

monocytes (Weisser et al. 2012). Unknown constituents of lymph may be required for LN maintenance, as shown by experimental lymphatic occlusion.

\section{PHENOTYPIC CHARACTERIZATION}

Studies have focused mainly on resident, rather than monocyte-derived recruited cells, in both spleen and LN. In this section, we describe some of the characteristic antigen markers that have been used (Fig. 3) (Taylor et al. 2005) and compare the lymphohematopoietic macrophages in mouse MZ and SCS with macrophages in splenic red pulp, bone marrow stroma, and liver Kupffer cells (Table 1).

F4/80 (Gordon et al. 2011), the widely expressed mouse macrophage plasma membrane marker, is strikingly absent on MMM, MZM, and SSM, but present on LN medullary macrophages. It is strongly exhibited by mouse red pulp macrophages, bone marrow stromal mac-

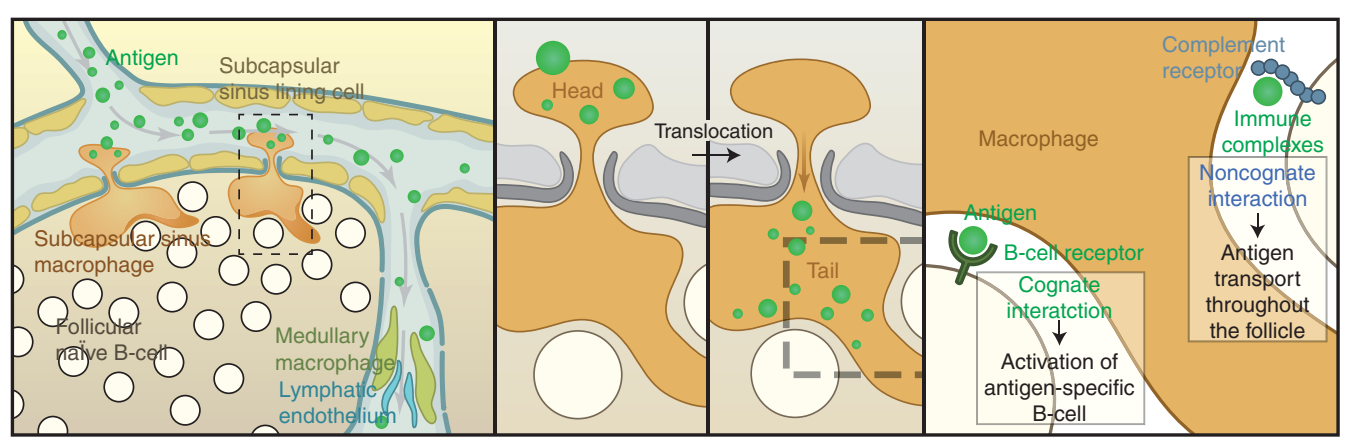

Figure 8. Schematic representation of subcapsular sinus macrophage function: antigen capture, delivery, and activation of B lymphocytes. For details, see text. (From Martinez-Pomares and Gordon 2007; reprinted, with permission, from the authors.) 
rophages, Kupffer cells, as well as mature macrophages in most tissues, including microglia, Langerhans cells in epidermis, and lamina propria macrophages of the intestine. It is weakly present on DC and monocytes and dim or absent on macrophages in T-cell-rich areas, such as the white pulp of spleen, interstitial regions of LN, and in Peyer's patches. The F4/80 antigen (EMR1) is also present on eosinophils in mouse; in humans, the homolog is restricted to eosinophils. The molecule belongs to a small leukocyte family of EGF-TM7 seven transmembrane GPCR-like adhesion receptors. Studies on the anterior chamber associated immune deviation (ACAID) model of ocular peripheral tolerance revealed that $\mathrm{F} 4 / 80$ is essential for this process; $\mathrm{F} 4 / 80^{+}$cells from the anterior chamber of the eye, possibly DC, migrate to the marginal sinus of spleen (Fig. 6), where they interact with CD4 and CD8 lymphocytes, and NKT cells, to induce systemic tolerance (Lin et al. 2005; van den Berg and Kraal 2005). Our studies (M Stacey, HH Lin, and S Gordon, unpubl.) have shown an uncharacterized ligand for F4/80 in the $\mathrm{MZ}$, consistent with the local absence of F4/80 antigen expression. Related myeloid molecules, EMR2 (human) and CD97 (mouse and human), have proteoglycan and complement regulatory membrane glycoprotein ligands.

CD169 (Klaas and Crocker 2012; O’Neill et al. 2013), although not unique to MMM and SSM, it is a characteristic, strongly expressed lectin-like marker for these specialized macrophages (Crocker and Gordon 1986, 1989). In spleen, it is dim on MZM and weakly present in red pulp macrophages, and variably present on medullary macrophages in LN. Originally termed sialoadhesin because of its ability to bind sialoconjugates on host and microbial ligands, CD169 is part of a leukocyte family of Siglecs, because it contains 17 Ig superfamily domains. In bone marrow, it is present on stromal macrophages at the center of hematopoietic cell clusters and plays a role in retention of immature myeloid cells (Chow et al. 2011). Expression on Kupffer cells is variable.

In our experience, it is not primarily an endocytic receptor, but well expressed on the plasma membrane of extensive macrophage cellular processes. Mouse serum/plasma contains an inducer of its expression by peritoneal macrophages in culture; in the CNS, only macrophages outside the blood - brain barrier are CD169 ${ }^{+}$ (Perry et al. 1992). Our studies (P Tree and S Gordon, unpubl.) implicated $\beta$ interferon (IFN) as a candidate inducer of its expression. It is plausible that exposure to plasma and possibly lymph contributes to its high expression in MMM and SSM, respectively; proximity to B-cell follicles may indicate a role in capture of potential tolerogenic/immunogenic antigens.

The best-characterized ligands of CD169 contain terminal $\alpha-2,3$ sialylated residues (e.g., heavily $O$-glycosylated molecules, such as CD43 and Mucin-1). Sialic acid-independent interactions have been reported with the Cysteine-rich domain of the mannose receptor, described below, and the galactose-type lectin, MGL.

Apart from its value as a macrophage-restricted marker, the CD169 knockout mouse shows only minor phenotypic changes, such as less severe autoimmunity. CD169 presents a target for antigen-liposome delivered nanoparticles (Chen et al. 2012); transgenic targeting has provided an excellent reporter for imaging and migration studies in vivo, as well as conditional ablation of MZM via diphtheria toxin receptor (Saito et al. 2001).

\section{MANNOSE RECEPTOR (MR, CD206)}

This well-characterized lectin-like endocytic receptor (Martinez-Pomares and Gordon 2012) is widely present on mature macrophages in many tissues, including sinusoidal red pulp and Kupffer cells, but is not present on macrophages in the MZ or SCS. However, a ligand for its amino-terminal cysteine-rich domain (CR-L) is strongly expressed by subpopulations of MMM and SSM. CD206 is absent on resting human blood monocytes, but readily expressed after serum-induced maturation of macrophages in cell culture. The Th2 cytokines IL- 4 and IL13 are prototypic inducers of CD206, markers of an alternative form of macrophage activation in vitro and in vivo, in contrast with selective down-regulation by interferon- $\gamma$, the inducer of classical, antimicrobial activation. CD206 is 
S. Gordon et al.

present on DC, and is structurally related to DEC-205, whose ligands are uncharacterized, compared with the recognition of terminal mannose, fucose or GlcNac residues by the eight calcium-dependent carbohydrate-recognition domains (CRD) of the MR. CD206 is also present on lymphatic endothelium and sinusoidal endothelia, for example, in liver, where, together with macrophages, it is a potent clearance receptor for mannose-terminal lysosomal hydrolases, a nonredundant function in CD206 knockout mice. CD206 mediates receptor-dependent endocytosis and macropinocytosis of endogenous and exogenous ligands, and was the first macrophage receptor found to recycle extensively. Although it contributes to binding of several viruses (e.g., HIV-1 and Dengue), mycobacteria, yeasts (Candida albicans), and parasites, such as Leishmania, it has not been shown to mediate efficient phagocytosis directly, perhaps depending on cooperation with other receptors or uncoating of its ligands.

Structural analysis has identified the multiple CRD as responsible for the above endocytic functions. The fibronectin II domain binds collagen, consistent with an additional adherence function, but, remarkably, the conserved cysteine-rich domain has turned out to be a distinct lectin for clearance of endogenous sulfated galactosyl ligands found, for example, on lutropin, a pituitary hormone. The use of chimaeric probes consisting of the cysteine-rich domain and human $\mathrm{Fc}(\mathrm{CR}-\mathrm{Fc})$, revealed selectivity for the MMM and SCSM, as well as FDC and tingible body macrophages in germinal centers (Martinez-Pomares et al. 1996; Taylor et al. 2004, 2005). The CR-Fc stains selectively those MMM in close proximity to B cells. This marker has been used to follow migration of MMM into white pulp follicles after immunization, and the reagent provides a tool for efficient and selective targeting of antigen to B cells (Berney et al. 1999).

\section{DC-SIGN/SIGNR1(CD209)}

SIGNR1 is one of a group of related mouse type II C-type lectins (CTLs), homologous to DC-SIGN of humans (Geijenbeek et al. 2002).
SIGNR1 is highly expressed by macrophage subpopulations in the MZ of spleen, SCS, and medullary sinus of the mouse, as first shown with mab ERTR9. In addition, it is variably present on other macrophages and DC. First described as a "nonintegrin ICAM3 grabbing lectin," it binds mannose and fucose, for example, on capsular polysaccharides of Streptococcus pneumoniae and dextran, and interacts with C1Q to activate complement, thus promoting uptake of capsulated bacteria, viruses, such as HIV, and apoptotic cells. Fluorescent and blocking antibodies, and CD209 knockout mice have been used extensively to study SIGNR1 function in virus infection and imaging.

Other CTLs (Drummond and Brown 2013), less defined in lymphohematopoietic tissue expression, include Dectin-1, -2, and -3, MCL, MINCL, and galectins. Several of these have known pathogen ligands and use well-characterized signaling pathways, for instance, the $\beta$ glucan-dependent uptake of yeasts via Dectin-1 signals through its hemi-ITAM motif, syk, and Card 9.

\section{MARCO}

This class A scavenger receptor, a type II transmembrane collagenous molecule, is an excellent constitutive marker for MZM, the large phagocytic macrophages of the splenic outer MZ. Closely related to the macrophage SRAI/II, it is a distinct gene product with overlapping, but different binding preference for polyanionic, modified host, and microbial ligands. Regulation of MARCO expression also differs from that of SRAI/II, which is widely present on tissue macrophages and mainly regulated by CSF1. In the unstimulated mouse, MARCO is strikingly restricted to the MZM and to a subpopulation of resident peritoneal macrophages. The MZM expression depends on the LT $\alpha 1 \beta 2$ receptor, whereas peritoneal macrophage expression depends on the microbial flora in the gut ( $\mathrm{S}$ Mukhopadhyay and S Gordon, unpubl.). However, most tissue macrophages can be induced to express MARCO by TLR ligands (e.g., during bacterial sepsis). It can also be induced on DC by sterile and infectious stimuli. 
Macrophages at the Lymphohematopoietic Interface

MARCO is an adhesion, phagocytic, and endocytic receptor (Chen et al. 2006; Mukhopadhyay et al. 2006). MARCO readily binds and takes up bacteria, such as unopsonized Neisseria meningitidis, but also binds B cells in the MZ (Karlsson et al. 2003). Together with SRAI/II, it contributes to the rapid clearance of particles, such as calciprotein-fetuin complexes from the circulation (Herrmann et al. 2012).

CD68, the pan macrophage and DC endosomal ag, various plasma membrane receptors, $\mathrm{FcR}, \mathrm{CD} 11 / \mathrm{CD} 18, \mathrm{CD} 11 \mathrm{c}$, and other integrins, have all been reported on MZ and SCSM, but these markers are shared with other leukocytes in spleen and LN. LYVE-1 is on LN macrophages and lymphatic endothelium. Madcam is a valuable marker for the sinus endothelium in spleen.

In summary, the metallophils and SSM express strikingly similar markers; splenic MZ, and LN medullary macrophages also have several corresponding markers. Their properties set them apart from bone marrow stromal macrophages, Kupffer cells, and other sinus-lining macrophages in other tissues. The combination of a cluster of highly expressed macrophage markers, such as CD169, SIGNR1, MARCO, and CR-Fc binding, by a population of F4/80 negative cells in a specialized anatomic location exposed to blood and lymph, suggests that they represent a distinctive sublineage. Further studies are required to determine their relationship to monocyte/macrophages and DC, their pro- duction and turnover, as well as functions to be considered next.

\section{FUNCTIONS OF MARGINAL ZONE \\ AND SUBCAPSULAR SINUS \\ MACROPHAGES}

\section{General Aspects}

The macrophages in the MZ and SCS are strategically placed to interact with pathogens and host cells and their products through a range of recognition receptors (Table 2), at the interface between blood and lymph with the immune system. They provide an innate recognition and clearance barrier to infection and serve as sentinels to initiate an adaptive response, if required, by delivering microorganisms and antigens to DC and other innate and lymphoid cells, by mobilization of hematopoietic cells including monocytes, and initiation of inflammatory cytokines and plasma cascades (MartinezPomares and Gordon 2007; Barral et al. 2010; Gray and Cyster 2012; den Haan and MartinezPomares 2013). Local interactions with stromal and vascular elements provide distinct microenvironments, which influence macrophage gene expression and functional responses. Depletion studies with clodronate, for example, have shown enhanced sensitivity to infection and facilitation of spread (Moseman et al. 2012). Transgenic ablation of $\mathrm{CD} 69^{+}$macrophages showed that they are required to cross-

Table 2. Receptors of marginal zone and subcapsular sinus macrophages

\begin{tabular}{|c|c|c|c|}
\hline Receptor & Nature & Ligand & Function \\
\hline Fc receptors ${ }^{\mathrm{a}}$ & Immunoglobulin superfamily & Immunoglobulin & Immune complex clearance \\
\hline Complement receptor $^{\mathrm{a}}$ & Integrin & Cleaved C3 & Opsonic uptake \\
\hline Toll-like receptors $^{\mathrm{a}}$ & Leucine-rich repeats & Multiple & Sensing microbes, altered self \\
\hline CD169 & Immunoglobulin superfamily & $\begin{array}{l}\text { Sialylated } \\
\text { glycoconjugates }\end{array}$ & $\begin{array}{l}\text { Adhesion, cell - cell/microbe } \\
\text { interactions }\end{array}$ \\
\hline SIGN-R1 & C-type lectin & Terminal mannosyl & $\begin{array}{l}\text { Clearance and cellular } \\
\text { interactions }\end{array}$ \\
\hline Mannose receptor & C-type lectin domains ${ }^{\mathrm{a}}$ & $\begin{array}{l}\text { Mannose, fucose, } \\
\text { GlcNac termini }\end{array}$ & $\begin{array}{l}\text { Adhesion and clearance of } \\
\text { glycoconjugates }\end{array}$ \\
\hline & Cysteine-rich domain & Sulfated sugars & Targeting to MZ and $\mathrm{LN}$ \\
\hline $\mathrm{MARCO}^{\mathrm{a}}$ & $\begin{array}{l}\text { Transmembrane collagenous } \\
\text { scavenger receptor }\end{array}$ & Selected polyanions & $\begin{array}{l}\text { Adhesion, uptake of microbes, } \\
\text { B-cell interactions }\end{array}$ \\
\hline
\end{tabular}

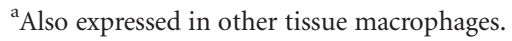


S. Gordon et al.

present apoptotic cell-associated antigens during antitumour activity (Asano et al. 2011). We discuss present knowledge of cellular responses in situ in relation to the general properties of macrophages, and bring out the need for further studies on these particular macrophage populations.

\section{ROLE OF MACROPHAGES IN THE MARGINAL ZONE}

The enhanced susceptibility of immature and splenectomised hosts to capsulated bacterial infection is well known. The lectins of the MMM and MZM, CD169, SIGNR1, and possibly others, may account for the loss of clearance of capsulated bacteria, such as S. pneumoniae, after macrophage depletion by clodronate, as shown by mab inhibition (SIGNR1) and the effect of gene knockout on phenotype. Similarly, MARCO knockout diminishes clearance of sterile, noninfectious particulates (Fig. 6). N. meningitidis is an excellent nonopsonic ligand for MARCO, and, independently, for CD169. Studies with SRAI/II knockout (Plüddemann et al. 2009) have shown a phenotype for Neisseria bacteraemia even in the presence of complement, a likely enhancer of opsonic phagocytosis through CD11/CD18 receptors, after classical, alternative, and lectin-activation by bacterial capsular polysaccharides.

Lectins play a similar role in direct or complement-mediated uptake of viruses, such as HIV and serum hepatitis virus.

It should be noted that phagocytic recognition is not necessarily nonspecific, because these nonopsonic receptors have a very broad range of ligands, are promiscuous, and often collaborate with other low-affinity receptors. Specific antibodies will enhance clearance of microbes and immune complexes through various FcR (Phan et al. 2009).

TLR can also collaborate with other plasma membrane and intracellular endosomal recognition receptors; their expression on MMM and MZM has not been adequately defined. The same holds true for NLR, RLR, and other cytosolic receptors for nucleic acids. Inflammasome activation has not been defined in these macrophages, to our knowledge (for LN, see below).

Phagocytosis of microbes is more evident in MZM, compared with MMM, but little is known about the cellular pathways that regulate uptake of particles and surface receptor complexes, or the subsequent intracellular fusion, acidification, digestion, or antigen processing/ presentation. The possible link of infection of MZ macrophages to autophagy has not been examined.

MMM express Tim-4 and Treml4 receptors for early- and late-stage apoptotic cells, in addition to uptake by tingible body macrophages. MFG-E8 and MER/Gas6 participate in phagocytic clearance of apoptotic B cells. MARCO on MZM has also been implicated in apoptotic cell uptake; deficient clearance by macrophages may contribute to autoimmunity. It is not clear whether uptake of apoptotic cells suppresses inflammation, as shown by IvIg administration, after which IL-33 up-regulates FcR 22 expression (Anthony et al. 2011).

Both MZM and MMM show IRF7 recruitment to phagosomes after Leishmania donovani infection. IRF deficiency gives rise to a small increase in the intracellular parasite load. Production of type 1 interferon by MZM and MMM contributes substantially to innate resistance to viral infection (e.g., HSV); its role in bacterial infection, such as mycobacterial bacteraemia, may be deleterious to host resistance.

MZM and MZ B cells collaborate as a cellular network in T-independent IgM responses to capsular polysaccharide. SIGNR1 expression depends on the continuous presence of $\mathrm{MZ}$ $B$ cells and is lost if the MZM are induced to migrate. SIGNR1 interacts with $\mathrm{C} 1 \mathrm{Q}$, initiating complement activation and binding by Bcell receptors and deposition on FDC. Attempts to distinguish the contribution of each macrophage subset to immune responses by condi-

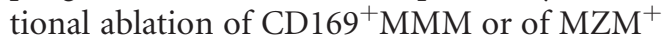
SIGNR1 via diphtheria toxin receptor has not proved sufficiently selective. Note that MZM may also express CD11c, complicating the interpretation of CD11c-targeted ablation.

Apart from the requirement for CSF-1 and LT in regulating marker expression in MMM 
and MZM, respectively, the cytokine-responsive pathways remain poorly defined, as are the transcription factors involved in selective gene and protein expression. The phenotype of CSF-1R deficiency is more severe than that for CSF-1; the possible role of IL-34 as a second ligand for CSF-1R has not been characterized in this context. It is likely that the proximity to B lymphocytes in the MZ, as in the SCS, provides the LT stimulus for induction via LT receptors, and continued expression of macrophage markers, whereas stromal fibroblasts are a likely source of CSF-1.

In addition to the induction of type 1 interferon in MZM and autocrine activation, the production of chemokines, cytokines, lysozyme, other enzymes, complement components, and low molecular weight metabolites (e.g., superoxide and NO) in response to microbial and apoptotic cell uptake, requires further study, with due consideration to the local in situ environment.

\section{ANTIGEN TARGETING TO THE MARGINAL ZONE}

Although confocal imaging methods have contributed greatly to research of dynamic antigen responses in $\mathrm{LN}$, to be discussed below, this has lagged behind in the less accessible spleen. However, targeting via the blood has brought to light new aspects of antigen delivery to the immune resident macrophages of the MZ. Antigen targeted to MMM and MZM is transferred to $\mathrm{CD}^{+}$DC, which depend on batf3 to induce strong CTL (den Haan and Kraal 2012); targeted antibody can also be cross presented to CD8T cells by DC. Therefore, macrophages of the $\mathrm{MZ}$ interact with both $\mathrm{B}$ cells and $\mathrm{DC}$ by uptake and transfer of ag.

We have exploited a novel mannose receptor-dependent pathway for clearance of glycoconjugates, to target antigen through the soluble cysteine-rich domain of the mannose receptor (Figs. 3 and 4) (Taylor et al. 2004). Human Fc-chimaeric proteins $(\mathrm{CR}-\mathrm{Fc})$ were used as antigen probes and for detection of delivery by immunocytochemistry. CR-Fc bound specifically to sulfated ligands expressed by a subpopulation of $\mathrm{CD} 169^{+}$MMM associated with $\mathrm{IgD}^{+} \mathrm{B}$ lymphocytes. Although the normal function of this clearance pathway may promote noninflammatory disposal of host ligands bound by the MR through carbohydrate recognition domains, targeting by $\mathrm{CR}-\mathrm{Fc}-\mathrm{ac}-$ tivated B cells and induced specific IgG responses. Mutational analysis of the CR-Fc established the specificity of targeting. Soluble MR, shed by TACE-like metalloproteinases from the surface of APC (e.g., after phagocytic stimulation) (Gazi et al. 2011), could similarly interact with MMM subpopulations and modulate B-cell responses.

Antigen targeting to DC via the closely related DEC-205 has been used to enhance antibody responses; the endocytic compartment reached by CR-L targeting of macrophages and its possible role in antigen processing and presentation have not been determined. Because MMM are inefficient endocytic macrophages, it is possible that bound protein is not internalized and digested, but delivered intact to other APC, B cells, and DC. The expression and role of $\mathrm{MHC}$ class II and costimulatory molecules by MMM remain unclear.

\section{ROLE OF MACROPHAGES IN SUBCAPSULAR SINUS AND MEDULLA OF LYMPH NODES}

SSM on the floor of the SCS, over follicles, are quick to capture lymph-borne substances, including virus particles, through lectins, scavenger receptors, and CR3, but are poorly endocytic. In contrast, MSM take up large amounts of material into conspicuous phagolysosomes. The long tails of SSM are stable, unlike more motile DC, and are anchored by the extracellular matrix. In rodents, SSM readily pick up ferritin, colloidal carbon, liposomes, and opsonized antigen. Opsonization increases electron microscopic evidence of internalization and degradation. Depletion by clodronate is slower than for medullary macrophages, consistent with differences in endocytic activity. SSM retain phycoerythrin labeled immune complexes (IC), which move along their surface to follicles; two-photon imaging shows their capture and transfer to B cells. Viruses, ag-loaded 200-nm 
S. Gordon et al.

beads, and IC bind to SSM heads, which translocate without internalization, and present these particulates on their tails to follicular B cells randomly migrating through the dense net of tails. Cognate B cells are activated directly from SSM via BCR. Opsonized antigen also activates noncognate $\mathrm{B}$ cells via $\mathrm{CR} 1$ and CR2, delivered to FDC as IC aggregates. SSM express ICAM-1 and VCAM1, which may assist transfer.

The role of SSM and MSM in innate immunity has been studied extensively by several groups (Gonzalez et al. 2010a; Moseman et al. 2012). SSM may transfer antigen intact to B cells or via DC. Kastenmuller, Germain, and colleagues (Kastenmuller et al. 2012) have investigated the role of LN macrophages as innate sentinel cells. CD169 ${ }^{+}$SSM and medullary macrophages $\left(\mathrm{F} 4 / 80^{+}\right)$, trap a range of pathogens including VSV, MVA, Pseudomonas, and S. typhi. SSM express IL-18, generated from pro-IL-18 by caspase 1 , and IL-1 $\beta$, depending on extra/intracellular pathogen virulence. Type 1 IFN and IL12 activate prepositioned NKT, NK, $\gamma / \delta$ T cells, plasmacytoid DC, and novel $\mathrm{CD}^{+} \gamma \delta \mathrm{T}$ innate cells to produce IFN- $\gamma$, which activates SSM and medullary macrophages to express iNOS. PMN recruitment depends on IL-1 $\beta$ production as a result of pyroptosis. This innate immune response limits systemic spread of pathogens to the spleen and can be destroyed by clodronate. DCs are present in a different location, for adaptive responses.

SSM and B cells are closely associated; B cells are a source of LT $\alpha 1 \beta 2$, also required for SSM maintenance, allowing viral replication, balanced by type 1 IFN production. A distinct pathway has been reported for influenza virus infection, by Carroll and colleagues (Gonzalez et al. 2010b), involving CD169 ${ }^{+} \mathrm{SIGNR}^{+}$SSM, which depends on complement opsonization via a lectin activation pathway.

\section{MEDULLARY SINUS MACROPHAGES (MSM)}

After trafficking through conduits, lymph encounters the actively phagocytic MSM before exit through efferent lymphatics. MSM play an important role in determining survival and clearance of short-lived early plasma cells. MSM variably express CD169, CR3, SIGNR1, MARCO, MR, Lyve-1, as well as F4/80. Cyster and colleagues (Gray and Cyster 2012) distinguish macrophages in the sinuses (low acid phosphatase, high nonspecific esterase) from those in the cords, (opposite expression). In the mouse, medullary cord macrophages lack CD169, but express F4/80.

MSM adhere to sinus walls and reticular fibers in the lumen, which also contains lymphocytes, variable numbers of plasma cells, depending on immunization, and small numbers of DC.

Antigens accumulate in highly active large phagocytic MSM, with heterogeneous lysosomes, unlike the less phagocytic cord macrophages. MSM take up apoptotic plasma cells, but macrophages in cords also provide trophic products, such as APRIL, promoting plasma cell survival.

Medullary macrophages take up and destroy viruses, whereas SSM (and MMM) are permissive for a range of virus infections (e.g., VSV, vaccinia, CMV), as well as toxoplasma, especially if type 1 interferon levels are reduced experimentally.

$\mathrm{CD}^{+} \mathrm{T}$ cells could be activated directly or via DC transfer, which is more effective. Presentation by SSM stimulates some CD4 T-cell proliferation, but is not good at generating CD8 effector cells. Toxoplasma infected SSM can present antigen in the context of MHCI for killing by CD8 T cells, but may lack sufficient costimulation. SSM are also able to present CD1d-restricted microspheres coated with $\alpha$-galactosyl ceramide liposomes to NKT cells.

LNs contain additional $\mathrm{CD}^{+} 8^{+}$macrophages, including interfollicular cells interacting with various innate and adaptive cells, especially after immune activation. Macrophages also extend more deeply along the $\mathrm{B}-\mathrm{T}$ boundary, or into T-cell zones.

\section{ROLE OF LIPIDS}

Afferent lymph reaching mesenteric LN is rich in absorbed lipids and microbial products. The expression of macrophage surface and intracellular sensors is regulated by, and, in turn, influ- 
ences their phenotype, as does their location along the path of lymphatic flow. The scavenger, Toll- and lectin-like receptors are responsive to lipid components in lymph. Knockout studies with Angptl4-deficient mice, for example, have revealed defective regulation of short chain fatty acids and dramatic changes in triglyceride metabolism. Mesenteric LN expand enormously, with extensive formation of multinucleated $\mathrm{F} 4 / 80^{+}$giant cells, the result of macrophage fusion. The role of steroid and other lipid ligands, vitamins A and D, and of transcription factors, such as PPARs in SCM, has not been explored.

\section{Conclusion}

Above all, the question remains of APC function of SSM and MSM, compared with DC and B cells, and activation of CD4 T-lymphocyte subsets, Th1, $-2,-17$, regulatory $\mathrm{T}$ cells, and NKT cells.

There is a striking similarity between LN SSM and MMM with regard to CD169 and other recognition molecule expression, their dependence on CSF-1, LT, and B lymphocytes, and proneness to viral infection at the lymphohematopoietic interface (Table 3); however, SSMs have been reported to capture immune complexes more readily than MMM. It is possible

Table 3. Shared properties of marginal zone, subcapsular sinus and medullary macrophages

Interface: blood/lymph

Proximity to innate and adaptive myeloid and lymphoid cells

Induction and regulation of B- and T-cell responses

Capture and disposal of apoptotic cells/role in autoimmunity/variably phagocytic

Postnatal development

Host defense: clearance of capsulated bacteria, polysaccharides, viruses, other bacteria

Clearance of sterile particles (outer MZ)

Antigen capture and delivery to APC

Inflammasome procaspase 1 store/activation (SSM, not reported for MZ)

Secretion of proinflammatory cytokines, IL-1 $\beta$, type I interferon, IL-12, chemokines, NO (incomplete information) that MZM and MSM, both enhanced phagocytic populations, represent homologous populations in spleen and LN. These tissue-specific similarities and differences in macrophage function may arise by differentiation or local environmental influences, such as the extracellular stroma or vasculature.

\section{SPECIES DIFFERENCES}

The human and rodent spleen and LN display obvious species differences in marker expression; Steiniger and colleagues (1997) found CD169 expression in interfollicular regions of human spleen, which lack the characteristic $\mathrm{MZ}$ of rodents. The CR-Fc (mouse) probe also shows differences in expression of ligands in human spleen, as do the MR and probes for MR CRD ligands (Martinez-Pomares et al. 2005; Steiniger et al. 2006). Human red pulp contains macrophages in splenic cords, which express CD68 and CD163, but not MR or DCSIGN. The marginal sinus is absent, but the perifollicular area contains sinuses and bloodfilled spaces without an endothelial cell lining. MSMs express DC-SIGN, MARCO, and LYVE-1 on both macrophages and endothelium. SSM/ MSM are not well defined, but express CD14 and CD68. Unlike mice, human SSM and MSM express DC-SIGN; CD169 $/$ DC-SIGN $^{+}$ macrophages are perifollicular, surrounding capillaries.

We conclude that although there may well be homologous sinusoidal macrophage populations in human and mouse lymphohematopoietic organs, a great deal more has to be learned by the study of resting and activated human LN, as well as spleen, to establish bona fide equivalent functional populations.

\section{CONCLUSIONS, QUESTIONS, AND SUGGESTIONS FOR FURTHER STUDY}

In this article, we have focused on a group of resident sinusoidal macrophages in spleen and LN, reviewed what we know concerning their properties and functions, and assessed gaps in our knowledge. Their study over five decades owes much to pioneering studies by John Hum- 


\section{S. Gordon et al.}

phrey, Georg Kraal, Jason Cyster, Luisa Martinez-Pomares, and their collaborators, as well as other investigators interested in the initiation of innate and adaptive immunity to virus infection and immunogenic stimulation. We propose that these macrophages are at the center of a highly specialized and important immunological function, which is best studied in the context of their living environment. Unlike surface and mucosal epithelial barriers, they provide defense against blood- and lymphborne pathogens with which they are in direct contact, but also monitor and clear endogenous host molecules and dying cells without necessarily activating immunity and inflammation. Of course, they share capture and disposal, as well as trophic and defense functions, with other resident tissue macrophages, especially in liver, bone marrow stroma, and splenic red pulp. Furthermore, they overlap with other myeloid cells, such as DC in antigen uptake, processing, and presentation, and in clearance and homeostasis with sinusoidal endothelial cells. Nevertheless, it is worthwhile to distinguish their nature and functions as important variations of the macrophage phenotype, and to approach their investigation in an appropriate way.

\section{Importance}

Pathogens, such as HIV, hepatitis virus, capsulated bacteria, such as $S$. pneumoniae and meningococci, as well as Mycobacterium tuberculosis and Plasmodium falciparum have potentially catastrophic effects on the host when disseminated through blood, as do needle stick injury, transfusions, and narcotic abuse. What makes the lymphohematopoietic interface special is the close proximity of the sinus lining and associated phagocytic macrophages to other cells of the innate and adaptive immune response, especially B lymphocytes and DCs. However, equally important is the limitation and suppression of inappropriate immunity and potential tissue injury to modified host components, a form of peripheral tolerance, which can give rise to autoimmunity. Persistence of sterile and infectious agents in macrophages that are compromised in antimicrobial resistance or degradation contribute to chronic infection and inflammation, which promotes further destruction of this specialized compartment. All vaccination strategies and the use of adjuvants depend on understanding of this critical tissue compartment. Finally, malignant cells can interact with macrophages at the lymphohematopoietic interface, limiting cancer spread to spleen, while favoring lymph node secondary invasion, whereas lymphoma metastasis, in contrast, involves both tissues.

\section{Nature}

We have focused our discussion on the macrophages of the splenic MZ, the metallophils, and their more phagocytic partner in the outer $\mathrm{MZ}$, and on LN SSMs, and their phagocytic, albeit more separated, macrophages in the medulla, but in contact with the same lymphatic stream. In the mouse, there is good correspondence of markers between these populations, whereas in humans, there is limited knowledge of markers and anatomical differences but functional similarities. The MMM and SSM capture, but seem not to internalize, particles efficiently compared with MZM and MSM, respectively. Recognition by plasma membrane molecules may seem nonspecific ("flypaper model"), but we believe the multiplicity of nonopsonic and opsonic receptors (lectins, scavenger, and complement receptors, among others not yet defined) endow these macrophages with a remarkable capacity to recognize a broad range of soluble and particulate ligands. Single markers, such as CD169, SIGNR1, and MARCO are suggestive, but not sufficient to characterize such macrophages. The absence of F4/80 on both MMM and SSM is striking, reminiscent of its absence on osteoclasts. The origin of these populations needs further study; postnatal development of secondary lymphoid structures argues against yolk sac and foetal liver origin, as does reconstitution by bone marrow after clodronate depletion. The role of CSF-1 and perhaps IL-34, for MMM and SSM development and LT for MZM and SSM, needs to distinguish marker expression, from the presence or absence of macrophages and other components, such as 
Macrophages at the Lymphohematopoietic Interface

endothelium and B cells. The stromal microenvironment is also heterogeneous and still poorly defined. A further problem that needs more study is the life history of these distinct macrophage populations, their recruitment, survival, proliferation, emigration, and death. The fate of newly recruited monocytes after infection, for example, has not been fully determined.

The regulation of phagocytic uptake in macrophages is incompletely understood. Apart from the functional state and interactions of surface receptors, which contain or lack internalization and signaling motifs, the role of the cytoskeleton (Batista and Dustin 2013) and of cross talk among signaling pathways in these sinusoidal macrophages are complex and unknown. Interactions with TLR and other surface molecules are also undefined. In truth, we still do not fully understand the discrimination between "foreign" and "modified self" by any macrophages. The dynamics of surface receptor fluidity and interactions are relevant to transfer hypotheses; the delivery by MR CR-Fc provides a potential mechanism for targeting of circulating ligands. Shedding, bleb, and nanotube formation, or induced migration, are other possible mechanisms for interactions with DC and $\mathrm{B}$ cells, which are highly motile compared with resident MMM and SCM. Interactions with other innate and adaptive cells, endothelium, and stromal cells may use the same and additional surface receptors.

The intracellular recognition, induced secretory responses, and fate of internalized material is also poorly characterized in the phagocytic MZM and MSM; this is critical to the balance between immune activation and suppression (e.g., after uptake of apoptotic B cells and plasma cells), and the balance between humoral and cellular immunity. Pathogens evolve evasion mechanisms to avoid capture and ingestion, or to facilitate their uptake by those macrophages that are relatively deficient in antimicrobial resistance mechanisms, such as type I interferon, the respiratory burst and i-NOS. Finally, the entire pathway of signaling and gene expression (chromatin, transcription, microRNA, posttranscriptional and translational control) remains to be examined in these cells.
Investigation and Manipulation

An appreciation of anatomy is essential to the study of lymphohematopoietic immunobiology. Most of our knowledge derives from mab production and, in situ analysis in the mouse, traditionally by microscopy and immunocytochemistry, and, recently, by sophisticated twoand three-dimensional multiphoton, confocal analysis, pioneered by Ron Germain and his colleagues (Gerner et al. 2012). In vivo functional studies date from early clearance studies, more recently reinforced by genetic manipulation of mice. The development of a clodronate liposome depletion method by Van Rooijen and colleagues has been widely used, in spite of limitations; conditional ablation based on highly expressed receptors, such as CD 169 and SIGNR1, also may lack specificity in their ability to discriminate between MMM and MZM, for example, and efficacy. Mab and soluble receptors (e.g., for targeting LT and its receptor) have helped to avoid the problem of regional differences in LN development in transgenic animals. As noted, heterogeneity of LN arising from differing drainage of lymph from gut and peripheral sites, such as skin, should also be borne in mind.

Of course, and not always fully appreciated, is the difficulty of isolating a minor population of highly stellate MMM or SCM, in terms of yield, damage, and artifacts. Nevertheless, the striking expression of marker antigens in situ makes it possible to relate their structure to function. A present limitation is the need to use multiple markers on the same tissue sections, but there is ongoing progress in this area. In humans, more markers are needed, apart from material for investigation, perhaps more easily solved for LN than spleen, especially where normal controls are required.

Nevertheless, depending on the availability of specific antibodies, in situ single cell analysis of many cellular properties mentioned above, can be significantly expanded. Laser capture microscopy provides limited numbers of cells for microarray and proteomic analysis, but can be used to identify selectively expressed transcription factors and other molecules for further validation in mouse and man. 
S. Gordon et al.

A new resource, relatively easy to undertake, would be to screen mutants generated by ENU mutagenesis or by programs of genome wide knockout. Hypomorphs, generated by mutagenesis, should be more useful in retaining local cellular interactions. The known immunocytochemical markers, such as CD169, SIGNR1, and MARCO could be used as first screen; follow up clearance and immunological assays should detect functional differences.

Induced pluripotent cell technology (IPS) would ultimately pose a demanding test to recapitulate the special phenotype of MMM and SCM in vitro. A fascinating new tool to begin to understand the species differences and the role of stroma and hematopoietic contributions, could take advantage of humanized mice (Manz 2007), where technology is progressing for myeloid as well as lymphoid reconstitution.

\section{CONCLUSION}

We propose the term sinusoidal immunity to emphasize the special functions of selected sinusoidal macrophages at the lymphohematopoietic interface in spleen and LNs. Their distinctive phenotype sets them apart from other sinusoidal macrophages in bone marrow, liver, and splenic red pulp, which share some of their functions. In a sense, it refines the now abandoned historic concept of the reticuloendothelial system, which emphasized the particle clearance function of these and other sinus-lining macrophages, irrespective of their close relationship to resident immune cells. The possible immunologic functions of sinusoidal true endothelial cells, which express similar clearance receptors remain to be established. We believe that the adoption of a different terminology will stimulate further studies of their unusual properties, similar to recognition of mucosal immunity as a distinct subject for investigation.

\section{ACKNOWLEDGMENTS}

We thank members of our group and many collaborators for helpful discussions. Work in the laboratory was supported by grants from the
Medical Research Council, UK, the Wellcome Trust, and Arthritis Research, UK.

\section{REFERENCES}

Anthony RM, Kobayashi T, Wermeling F, Ravetch JV. 2011. Intravenous gammaglobulin suppresses inflammation through a novel $\mathrm{T}_{\mathrm{H}} 2$ pathway. Nature 475: 110-113.

Asano K, Nabeyama A, Miyake Y, Qiu CH, Kurita A, Tomura M, Kanagawa O, Fujii S, Tanaka M. 2011. CD169-positive macrophages dominate antitumor immunity by crosspresenting dead cell-associated antigens. Immunity 34: $85-95$.

Barral P, Polzella P, Bruckbauer A, van Rooijen N, Besra GS, Cerundolo V, Batista FD. 2010. CD169 $9^{+}$macrophages present lipid antigens to mediate early activation of $i$ NKT cells in lymph nodes. Nat Immunol 11: 303-312.

Batista FD, Dustin ML. 2013. Cell:cell interactions in the immune system. Immunol Rev 251: 7-12.

Benedict CA, De Trez C, Schneider K, Ha S, Patterson G, Ware CF. 2006. Specific remodeling of splenic architecture by cytomegalovirus. PLoS Pathog 2: e16.

Berney C, Herren S, Power CA, Gordon S, Martinez-Pomares L, Kosco-Vilbois MH. 1999. A member of the dendritic cell family that enters B cell follicles and stimulates primary antibody responses identified by a mannose receptor fusion protein. J Exp Med 190: 851-860.

Castagnaro L, Lenti E, Maruzzelli S, Spinardi L, Migliori E, Farinello D, Sitia G, Harrelson Z, Evans SM, Guidotti LG, et al. 2013. Nkx2-5 $5^{+}$islet ${ }^{+}$mesenchymal precursors generate distinct spleen stromal cell subsets and participate in restoring stromal network integrity. Immunity 38: 782791.

Chen Y, Pikkarainen T, Elomaa O, Soininen R, Kodama T, Kraal G, Tryggvason K. 2005. Defective microarchitecture of the spleen marginal zone and impaired response to a thymus-independent type 2 antigen in mice lacking scavenger receptors MARCO and SR-A. J Immunol 175: 8173-8180.

Chen WC, Kawasaki N, Nycholat CM, Han S, Pilotte J, Crocker PR, Paulson JC. 2012. Antigen delivery to macrophages using liposomal nanoparticles targeting sialoadhesin/CD169. PLoS ONE 7: e39039.

Cheong C, Matos I, Choi JH, Dandamudi DB, Shrestha E, Longhi MP, Jeffrey KL, Anthony RM, Kluger C, Nchinda G, et al. 2010. Microbial stimulation fully differentiates monocytes to DC-SIGN/CD209 ${ }^{+}$dendritic cells for immune T cell areas. Cell 143: 416-429.

Chow A, Lucas D, Hidalgo A, Mendez-Ferrer S, Hashimoto D, Scheiermann C, Battista M, Leboeuf M, Prophete C, van Rooijen N, et al. 2011. Bone marrow $\mathrm{CD} 169^{+}$macrophages promote the retention of hematopoietic stem and progenitor cells in the mesenchymal stem cell niche. $J$ Exp Med 208: 261-271.

Crocker PR, Gordon S. 1986. Properties and distribution of a lectin-like hemagglutinin differentially expressed by murine stromal tissue macrophages. J Exp Med 164: $1862-1875$.

Crocker PR, Gordon S. 1989. Mouse macrophage hemagglutinin (sheep erythrocyte receptor) with specificity for 
sialylated glycoconjugates characterized by a monoclonal antibody. J Exp Med 169: 1333-1346.

Crocker PR, Werb Z, Gordon S, Bainton DF. 1990. Ultrastructural localization of a macrophage-restricted sialic acid binding hemagglutinin, SER, in macrophage-hematopoietic cell clusters. Blood 76: 1131-1138.

Davies LC, Jenkins SJ, Allen JE, Taylor PR. 2013. Tissueresident macrophages. Nat Immunol 14: 986-995.

den Haan JM, Kraal G. 2012. Innate immune functions of macrophage subpopulations in the spleen. J Innate Immun 4: 437-445.

den Haan JM, Martinez-Pomares L. 2013. Macrophage heterogeneity in lymphoid tissues. Semin Immunopathol 35: 541-552.

Drummond RA, Brown GD. 2013. Signalling C-type lectins in antimicrobial immunity. PLoS Pathog 9: e1003417.

Gazi U, Rosas M, Singh S, Heinsbroek S, Haq I, Johnson S, Brown GD, Williams DL, Taylor PR, Martinez-Pomares L. 2011. Fungal recognition enhances mannose receptor shedding through dectin-1 engagement. J Biol Chem 286: 7822-7829.

Geijtenbeek TB, Groot PC, Nolte MA, van Vliet SJ, Gangaram-Panday ST, van Duijnhoven GC, Kraal G, van Oosterhout AJ, van Kooyk Y. 2002. Marginal zone macrophages express a murine homologue of DC-SIGN that captures blood-borne antigens in vivo. Blood 100: 29082916.

Gerner MY, Kastenmuller W, Ifrim I, Kabat J, Germain RN. 2012. Histo-cytometry: A method for highly multiplex quantitative tissue imaging analysis applied to dendritic cell subset microanatomy in lymph nodes. Immunity 37: 364-376.

Gonzalez SF, Kuligowski MP, Pitcher LA, Roozendaal R, Carroll MC. 2010a. The role of innate immunity in B cell acquisition of antigen within LNs. Adv Immunol 106: $1-19$.

Gonzalez SF, Lukacs-Kornek V, Kuligowski MP, Pitcher LA, Degn SE, Kim YA, Cloninger MJ, Martinez-Pomares L, Gordon S, Turley SJ, et al. 2010b. Capture of influenza by medullary dendritic cells via SIGN-R1 is essential for humoral immunity in draining lymph nodes. Nat Immunol 11: 427-434.

Gordon S. 2012. Macrophages and phagocytosis. In Fundamental immunology (ed. Paul WE). Lippincott, Williams and Wilkins, Philadelphia.

Gordon S, Hamann J, Lin HH, Stacey M. 2011. F4/80 and the related adhesion-GPCRs. Eur J Immunol 41: 24722476.

Gowans JL. 1991. First Medawar prize lecture. The recirculating small lymphocyte. Transplant Proc 23: 7-8.

Gray EE, Cyster JG. 2012. Lymph node macrophages. J Innate Immun 4: 424-436.

Hashimoto D, Chow A, Noizat C, Teo P, Beasley MB, Leboeuf M, Becker CD, See P, Price J, Lucas D, et al. 2013. Tissue-resident macrophages self-maintain locally throughout adult life with minimal contribution from circulating monocytes. Immunity 38: 792-804.

Herrmann M, Schafer C, Heiss A, Graber S, Kinkeldey A, Buscher A, Schmitt MM, Bornemann J, Nimmerjahn F Helming L, et al. 2012. Clearance of fetuin-A-containing calciprotein particles is mediated by scavenger receptorA. Circ Res 111: 575-584.

Hume DA, Robinson AP, MacPherson GG, Gordon S. 1983. The mononuclear phagocyte system of the mouse defined by immunohistochemical localization of antigen F4/80. Relationship between macrophages, Langerhans cells, reticular cells, and dendritic cells in lymphoid and hematopoietic organs. J Exp Med 158: 1522-1536.

Humphrey JH, Grennan D. 1981. Different macrophage populations distinguished by means of fluorescent polysaccharides. Recognition and properties of marginalzone macrophages. Eur J Immunol 11: 221-228.

Jenne CN, Kubes P. 2013. Immune surveillance by the liver. Nat Immunol 14: 996-1006.

Karlsson MC, Guinamard R, Bolland S, Sankala M, Steinman RM, Ravetch JV. 2003. Macrophages control the retention and trafficking of B lymphocytes in the splenic marginal zone. J Exp Med 198: 333-340.

Kastenmuller W, Torabi-Parizi P, Subramanian N, Lammermann T, Germain RN. 2012. A spatially-organized multicellular innate immune response in lymph nodes limits systemic pathogen spread. Cell 150: 1235-1248.

Klaas M, Crocker PR. 2012. Sialoadhesin in recognition of self and non-self. Semin Immunopathol 34: 353-364.

Kraal G. 1992. Cells in the marginal zone of the spleen. Int Rev Cytol 132: 31-74.

Kraal G, Schornagel K, Streeter PR, Holzmann B, Butcher EC. 1995. Expression of the mucosal vascular addressin, MAdCAM-1, on sinus-lining cells in the spleen. Am J Pathol 147: 763-771.

Kraal G, van der Laan LJ, Elomaa O, Tryggvason K. 2000. The macrophage receptor MARCO. Microbes Infect 2: 313-316.

Lin HH, Faunce DE, Stacey M, Terajewicz A, Nakamura T, Zhang-Hoover J, Kerley M, Mucenski ML, Gordon S, Stein-Streilein J. 2005. The macrophage F4/80 receptor is required for the induction of antigen-specific efferent regulatory T cells in peripheral tolerance. J Exp Med 201: $1615-1625$.

MacLennan IC. 2005. Germinal centers still hold secrets. Immunity 22: 656-657.

Manz MG. 2007. Human-hemato-lymphoid-system mice: Opportunities and challenges. Immunity 26: 537-541.

Martinez-Pomares L, Gordon S. 2007. Antigen presentation the macrophage way. Cell 131: 641-643.

Martinez-Pomares L, Gordon S. 2012. CD169 ${ }^{+}$macrophages at the crossroads of antigen presentation. Trends Immunol 33: 66-70.

Martinez-Pomares L, Kosco-Vilbois M, Darley E, Tree P, Herren S, Bonnefoy JY, Gordon S. 1996. Fc chimeric protein containing the cysteine-rich domain of the murine mannose receptor binds to macrophages from splenic marginal zone and lymph node subcapsular sinus and to germinal centers. J Exp Med 184: 1927-1937.

Martinez-Pomares L, Hanitsch LG, Stillion R, Keshav S, Gordon S. 2005. Expression of mannose receptor and ligands for its cysteine-rich domain in venous sinuses of human spleen. Lab Invest 85: 1238-1249.

Milicevic NM, Klaperski K, Nohroudi K, Milicevic Z, Bieber K, Baraniec B, Blessenohl M, Kalies K, Ware CF, Westermann J. 2011. TNF receptor-1 is required for the for- 


\section{S. Gordon et al.}

mation of splenic compartments during adult, but not embryonic life. J Immunol 186: 1486-1494.

Moghimi SM, Parhamifar L, Ahmadvand D, Wibroe PP, Andresen TL, Farhangrazi ZS, Hunter AC. 2012. Particulate systems for targeting of macrophages: Basic and therapeutic concepts. J Innate Immun 4: 509-528.

Morris L, Graham CF, Gordon S. 1991. Macrophages in haemopoietic and other tissues of the developing mouse detected by the monoclonal antibody F4/80. Development 112: 517-526.

Morris L, Crocker PR, Hill M, Gordon S. 1992. Developmental regulation of sialoadhesin (sheep erythrocyte receptor), a macrophage-cell interaction molecule expressed in lymphohemopoietic tissues. Dev Immunol 2: $7-17$.

Moseman EA, Iannacone M, Bosurgi L, Tonti E, Chevrier N, Tumanov A, Fu YX, Hacohen N, von Andrian UH. 2012. B cell maintenance of subcapsular sinus macrophages protects against a fatal viral infection independent of adaptive immunity. Immunity 36: 415-426.

Moussion C, Sixt M. 2013. A conduit to amplify innate immunity. Immunity 38: 853-854.

Mueller SN, Germain RN. 2009. Stromal cell contributions to the homeostasis and functionality of the immune system. Nat Rev Immunol 9: 618-629.

Mukhopadhyay S, Chen Y, Sankala M, Peiser L, Pikkarainen T, Kraal G, Tryggvason K, Gordon S. 2006. MARCO, an innate activation marker of macrophages, is a class A scavenger receptor for Neisseria meningitidis. Eur J Immunol 36: 940-949.

Nolte MA, Arens R, Kraus M, van Oers MH, Kraal G, van Lier RA, Mebius RE. 2004. B cells are crucial for both development and maintenance of the splenic marginal zone. J Immunol 172: 3620-3627.

O'Neill AS, van den Berg TK, Mullen GE. 2013. Sialoadhesin-A macrophage-restricted marker of immunoregulation and inflammation. Immunology 138: 198-207.

Perry VH, Crocker PR, Gordon S. 1992. The blood-brain barrier regulates the expression of a macrophage sialic acid-binding receptor on microglia. J Cell Sci 101: 201207.

Phan TG, Green JA, Gray EE, Xu Y, Cyster JG. 2009. Immune complex relay by subcapsular sinus macrophages and noncognate B cells drives antibody affinity maturation. Nat Immunol 10: 786-793.

Plüddemann A, Hoe JC, Makepeace K, Moxon ER, Gordon S. 2009. The macrophage scavenger receptor a is hostprotective in experimental meningococcal septicaemia. PLoS Pathog 5: e1000297.

Reizis B. 2012. Classical dendritic cells as a unique immune cell lineage. J Exp Med 209: 1053-1056.

Roozendaal R, Mebius RE, Kraal G. 2008. The conduit system of the lymph node. Int Immunol 20: 1483-1487.

Saito M, Iwawaki T, Taya C, Yonekawa H, Noda M, Inui Y, Mekada E, Kimata Y, Tsuru A, Kohno K. 2001. Diphtheria toxin receptor-mediated conditional and targeted cell ablation in transgenic mice. Nat Biotechnol 19: 746-750.

Schulz C, Gomez Perdiguero E, Chorro L, Szabo-Rogers H, Cagnard N, Kierdorf K, Prinz M, Wu B, Jacobsen SE, Pollard JW, et al. 2012. A lineage of myeloid cells independent of Myb and hematopoietic stem cells. Science 336: 86-90.

Steiniger B, Barth P, Herbst B, Hartnell A, Crocker PR. 1997. The species-specific structure of microanatomical compartments in the human spleen: Strongly sialoadhesinpositive macrophages occur in the perifollicular zone, but not in the marginal zone. Immunology 92: 307-316.

Steiniger B, Timphus EM, Barth PJ. 2006. The splenic marginal zone in humans and rodents: An enigmatic compartment and its inhabitants. Histochem Cell Biol 126: 641-648.

Taylor PR, Zamze S, Stillion RJ, Wong SY, Gordon S, Martinez-Pomares L. 2004. Development of a specific system for targeting protein to metallophilic macrophages. Proc Natl Acad Sci 101: 1963-1968.

Taylor PR, Martinez-Pomares L, Stacey M, Lin HH, Brown GD, Gordon S. 2005. Macrophage receptors and immune recognition. Annu Rev Immunol 23: 901-944.

van den Berg TK, Kraal G. 2005. A function for the macrophage F4/80 molecule in tolerance induction. Trends Immunol 26: 506-509.

Weisser SB, van Rooijen N, Sly LM. 2012. Depletion and reconstitution of macrophages in mice. J Vis Exp 66: 4105.

Wijffels JF, de Rover Z, Beelen RH, Kraal G, van Rooijen N. 1994. Macrophage subpopulations in the mouse spleen renewed by local proliferation. Immunobiology 191: 52-64.

Witmer-Pack MD, Hughes DA, Schuler G, Lawson L, McWilliam A, Inaba K, Steinman RM, Gordon S. 1993. Identification of macrophages and dendritic cells in the osteopetrotic (op/op) mouse. J Cell Sci 104: 1021-1029.

Yona S, Kim KW, Wolf Y, Mildner A, Varol D, Breker M, Strauss-Ayali D, Viukov S, Guilliams M, Misharin A, et al. 2013. Fate mapping reveals origins and dynamics of monocytes and tissue macrophages under homeostasis. Immunity 38: 79-91.

You Y, Myers RC, Freeberg L, Foote J, Kearney JF, Justement LB, Carter RH. 2011. Marginal zone B cells regulate antigen capture by marginal zone macrophages. J Immunol 186: $2172-2181$.

Zamze S, Martinez-Pomares L, Jones H, Taylor PR, Stillion RJ, Gordon S, Wong SY. 2002. Recognition of bacterial capsular polysaccharides and lipopolysaccharides by the macrophage mannose receptor. J Biol Chem 277: 4161341623.

Zindl CL, Kim TH, Zeng M, Archambault AS, Grayson MH, Choi K, Schreiber RD, Chaplin DD. 2009. The lymphotoxin $\mathrm{LT} \alpha_{1} \beta_{2}$ controls postnatal and adult spleen marginal sinus vascular structure and function. Immunity 30: 408-420. 


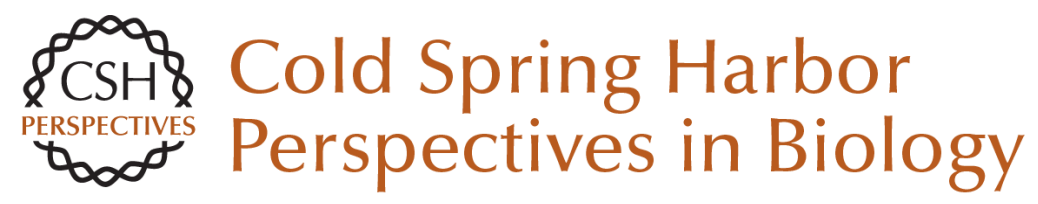

\section{Sinusoidal Immunity: Macrophages at the Lymphohematopoietic Interface}

Siamon Gordon, Annette Plüddemann and Subhankar Mukhopadhyay

Cold Spring Harb Perspect Biol 2015; doi: 10.1101/cshperspect.a016378 originally published online December 11, 2014

\section{Subject Collection Innate Immunity and Inflammation}

Group 2 Innate Lymphoid Cells in Health and

Disease

Brian S. Kim and David Artis

Inflammation and the Blood Microvascular

System

Jordan S. Pober and William C. Sessa

Sinusoidal Immunity: Macrophages at the

Lymphohematopoietic Interface

Siamon Gordon, Annette Plüddemann and Subhankar Mukhopadhyay

Allergic Inflammation--Innately Homeostatic Laurence E. Cheng and Richard M. Locksley

Approaching the Next Revolution? Evolutionary Integration of Neural and Immune Pathogen

Sensing and Response

Kevin J. Tracey

Inflammasomes

Marcel R. de Zoete, Noah W. Palm, Shu Zhu, et al.

IL-6 in Inflammation, Immunity, and Disease Toshio Tanaka, Masashi Narazaki and Tadamitsu Kishimoto
The Chemokine System in Innate Immunity

Caroline L. Sokol and Andrew D. Luster

Microbial Sensing by Toll-Like Receptors and

Intracellular Nucleic Acid Sensors

Surya Pandey, Taro Kawai and Shizuo Akira

Tumor Necrosis Factor Superfamily in Innate Immunity and Inflammation John Sedý, Vasileios Bekiaris and Carl F. Ware

\section{Emerging Principles Governing Signal}

Transduction by Pattern-Recognition Receptors Jonathan C. Kagan and Gregory M. Barton

Lipid Mediators in the Resolution of Inflammation Charles N. Serhan, Nan Chiang, Jesmond Dalli, et al.

\section{Transcriptional Control of Inflammatory Responses \\ Stephen T. Smale and Gioacchino Natoli}

DNA Degradation and Its Defects

Kohki Kawane, Kou Motani and Shigekazu Nagata

For additional articles in this collection, see http://cshperspectives.cshlp.org/cgi/collection/

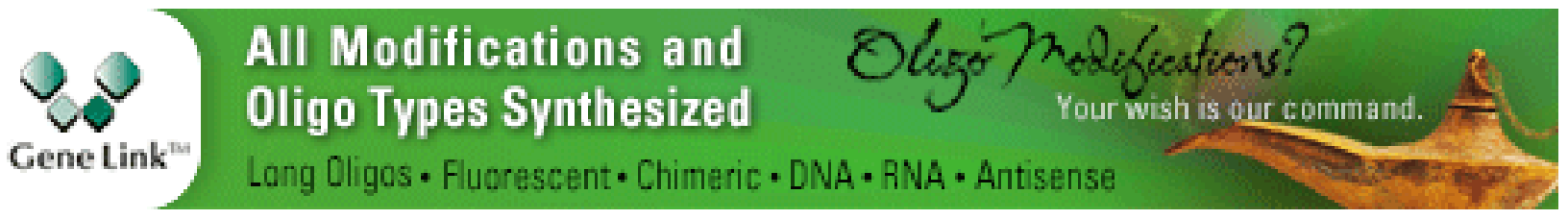

